\title{
A TEORIA DAS IDEIAS EM MALEBRANCHE: OBSERVAÇÕES SOBRE INTENCIONALIDADE, PENSAMENTO E SENSAÇÃO
}

The Theory of Ideas of Malebranche: Remarks on Intentionality, Thought and Sensation

Pedro Pricladnitzky *

Resumo: Neste artigo, pretendo examinar a maneira como Malebranche compreende a intencionalidade, característica das cognições humanas, e a sua relação com o desenvolvimento da teoria das ideias apresentada na Recherche de la Verité. Contrariando uma posição presente em diversos intérpretes de Malebranche, apresento uma interpretação na qual as sensações podem ser consideradas intencionais para Malebranche e que, dessa forma, a sua análise não conduz ao argumento que defende as modificações da alma como não representacionais.

Palavras-Chave: Intecionalidade; Ideias; Sensações; Malebranche.

Abstract: In this text, I intend to examine the way Malebranche understands intentionality, a characteristic of human cognition, and its relation to the development of the theory of ideas presented in Recherche de la Verité. In opposition with several of Malebranche's critics, I offer an interpretation in which sensations can be considered intentional for the author and, therefore, his analysis cannot be regarded as a starting point for the argument that modifications of the soul are not representational.

Keywords: $\mathbf{x x x}$; $\mathbf{x x x} ; \mathbf{x x x}$; $\mathbf{x x x}$.

\footnotetext{
* Doutor em Filosofia pela Universidade Federal do Rio Grande do Sul (UFRGS). Professor do Departamento de Filosofia da Universidade Federal do Rio Grande do Sul (UFRS). Artigo recebido em 28/07/2015 e aprovado para publicação em 10/05/2016.
} 
crítica de Malebranche ao caráter intrinsecamente representacional das modificações da substância pensante (mente) é fundamental 1 para a compreensão da sua teoria da cognição. Entretanto, não é claro qual é o processo argumentativo que o conduz a essa posição. Neste artigo, analiso alguns elementos que constituem a sua interpretação acerca da intencionalidade do pensamento que procuram esclarecer essa dificuldade interpretativa. Em um primeiro momento, apresento o conceito propriamente malebranchista de intencionalidade e como as sensações poderiam não ser reconhecidas como intencionais. Alternativamente, em um segundo momento, pretendo indicar uma interpretação onde as sensações podem ser consideradas como intencionais para Malebranhce. Por último, lanço uma hipótese que pretende identificar a origem do princípio de intencionalidade malebranchista.

Um elemento inequívoco do debate entre Antoine Arnauld e Nicolas Malebranche acerca da natureza da cognição humana é sua oposição no tratamento das ideias. Enquanto que, para Arnauld, as ideias são modos e, talvez os modos por excelência, da substância pensante; Malebranche afirma que as ideias são entidades realmente distintas da mente. É preciso salientar que não se trata apenas de uma divergência acerca da correta definição do conceito de ideia. Malebranche e Arnauld estão de acordo que é através das ideias que somos capazes de ter cognições das coisas no mundo. É pela natureza intrinsecamente representacional das ideias que somos capazes de conhecer o mundo. O que está em questão, todavia, é se a nossa capacidade de representar é derivada da própria natureza da substância pensante, isto é, se a mente é intrinsecamente representacional; ou se os modos da substância pensante não encerram em si o conteúdo de representação, isto é, se ela depende de uma composição com elementos que lhe são extrínsecos para ser capaz de ter cognição. No decorrer da extensa polêmica entre os dois autores, Malebranche é resoluto: as modificações da substância pensante não são representacionais, toda representação que ocorre em um ato de cognição do homem envolve um elemento que é extrínseco à mente humana.

Parece ser um consenso entre os intérpretes que a recusa das modificações representacionais está associada à interpretação malebranchista da intencionalidade dos pensamentos. A divergência ocorre, entretanto, na tentativa de determinar quais características do princípio de intencionalidade levam a um antipsicologismo das ideias, ou que argumentos podem dele ser derivados para defender tal posição. Alguns intérpretes ${ }^{1}$, na tentativa de identificar as razões que acarretam essa tese, afirmam que da conjunção entre o estabelecimento da intencionalidade como uma relação ordinária e a análise das sensações, uma variedade das modificações da substância

\footnotetext{
${ }^{1}$ Estou me referindo a Nicholas Jolley e a Steven Nadler. Cf. o livro de Jolley The Light of the Soul p.60; e três textos de Nadler: Malebranche and Ideas p. 80; Arnauld and the Cartesian Philosophy of Ideas p. 175-8; e "Intentionality in the Arnauld-Malebranche Debate" p. 74.
} 
pensante, é possível derivar a tese de que nem todo pensamento é intencional; o que, por sua vez, seria equivalente a afirmar que a intencionalidade não é uma característica essencial ao pensamento. Disso, poderíamos concluir que ainda que existam pensamentos que possuem intencionalidade e que essa seja uma característica fundamental da atividade cognitiva do homem, pois é a partir dela que somos capazes de conhecer objetos, a representacionalidade não é uma característica intrínseca às modificações da substância pensante. ${ }^{2}$ Com isso, vemos que a recusa das modificações representacionais repousa em uma oposição radical à tendência cartesiana de imputar intencionalidade em toda atividade mental. Malebranche estaria, portanto, muito mais afastado de Descartes do que se costuma apresentar. ${ }^{3}$

Ainda que existam passagens de Malebranche que pareçam corroborar essa leitura, pretendo mostrar que essa interpretação é problemática. Em um primeiro momento, apresento o conceito propriamente malebranchista de intencionalidade e como as sensações poderiam não ser reconhecidas como intencionais. Alternativamente, em um segundo momento, pretendo indicar uma interpretação onde as sensações podem ser consideradas como intencionais para Malebranhce. Por último, lanço uma hipótese que pretende identificar a origem do princípio de intencionalidade malebranchista.

Em diversas passagens ${ }^{4}$ da sua obra Malebranche apresenta o que ficou conhecido na literatura como o princípio voir rien. Dentre essas passagens, cabe salientar uma passagem do livro IV da Recherche de La Verité e uma passagem do primeiro diálogo dos Entretiens sur La Métaphysique. ${ }^{5}$ No livro IV, Malebranche afirma: “É certo que o nada ou o falso não é visível ou inteligível. Ver o nada, não é ver. Pensar o nada, não é pensar, é impossível perceber uma falsidade".${ }^{6}$ A passagem da Recherche é a primeira ocorrência desse princípio na filosofia de Malebranche. Mas, talvez, a passagem mais completa seja a apresentada nos Entretiens:

“Eu penso sobre uma variedade de coisas; sobre um número, um círculo, uma causa, certas entidades particulares, sobre o ser. Agora, tudo isso existe, ao menos enquanto eu penso nessas coisas. Certamente, quando eu

\footnotetext{
${ }^{2}$ As relações entre intencionalidade e representacionalidade dos atos mentais são complexas e demandam um texto à parte. Nesse sentido, gostaria apenas de salientar que ser intencional e ser representacional parecem ser aspectos indissociáveis de atos mentais que são sobre alguma coisa.

${ }^{3}$ Cf. ALQUIÉ, F. Le Cartésianisme de Malebranche.

${ }^{4}$ Cf. OM II, 99; OM II, 103; OM II, 372; IV, 72-4; VI, 202; IX, 910; IX, 946-54; IX, 1009; IX, 1065; XII, 35; XV, 5-9; XVII-1, 303. As referências às obras de Malebranche serão feitas segundo a edição dirigida por André Robinet e publicadas pela J. Vrin. 'OM' se refere abreviadamente a Oeuvres Complètes de Malebranche; em algarismos romanos temos a indicação de volume e em algarismos arábicos a indicação da página. A tradução para o português é de minha responsabilidade.

${ }^{5}$ A partir desse momento me referirei aos textos apenas por Recherche e Entretiens.

${ }^{6}$ OC II, 99.
} 
penso em um círculo, em um número, no ser, no infinito, ou em um certo ser finito; eu percebo realidades. Pois se o círculo que eu percebo fosse nada, ao pensá-lo eu estaria pensando sobre nada, o que é equivalente a não pensar sobre coisa alguma. Então, eu estaria pensando e não pensando ao mesmo tempo! E, outro ponto: o círculo que eu tenho na mente possui propriedades que nenhuma outra figura possui. Assim, o círculo existe quando eu penso nele, pois o nada não possui propriedades - não se coloca a questão a respeito de um nada que é diferente de outro pois possuem propriedades distintas". ${ }^{7}$

Malebranche parte da constatação de que todo pensamento e que toda percepção é pensamento ou percepção de alguma coisa. São atos mentais que se direcionam para alguma coisa, ou intencionam algum objeto. Isso, por sua vez, parece ser apenas a constatação da transitividade do pensar e do perceber, algo que por si só não acarretaria maiores implicações filosóficas. A peculiaridade de Malebranche, da perspectiva cartesiana, se encontra na posição que ele toma a respeito daquilo a que as percepções e os pensamentos se direcionam. As coisas que são pensadas ou percebidas devem existir ou terem realidade. Caso não existam, pensamentos e percepções seriam vazios, o que implicaria em uma contradição, pois na medida em que, por definição, o pensamento supõe um objeto, um pensamento vazio é um não pensamento. Para dar conta da intencionalidade dos pensamentos e das percepções, é preciso afirmar que o pensamento é de fato direcionado para algum objeto que está realmente presente. Nessa leitura, a intencionalidade é um tipo ordinário de relação entre o pensamento e seu objeto. Relações ordinárias demandam a existência de ambos relata. Por exemplo, 'estar à direita de' ou 'ser a causa de' só podem ser estabelecidas por duas entidades distintas. ${ }^{8}$

Toda operação mental, portanto, para ser considerada como intencional deve possuir um objeto efetivamente existente para o qual ela se direciona. Nesse contexto, seriam as sensações intencionais? Descartes, por exemplo, ao analisar as cognições que estão associadas aos sentidos (e.g. cor, sabor, odor, dor, prazer, etc.) as classifica como obscuras e confusas; sendo, aparentemente, apenas efeitos na mente de certos movimentos da extensão. Elas não seriam capazes de apresentar algum objeto para a mente. Cito Descartes:

“Quanto às outras coisas, como a luz, as cores, os sons, os odores, os sabores, o calor, o frio e as outras qualidades que caem sob o tato, encontram-se em meu pensamento com tanta obscuridade e confusão que ignoro mesmo se são verdadeiras ou falsas e somente aparentes, isto é, se as ideias que concebo dessas qualidades são, com efeito, as ideias de algumas coisas reais ou se não me representam apenas seres quiméricos que não podem existir (...) pode, no entanto, ocorrer que se encontre nas ideias uma certa

\footnotetext{
${ }^{7}$ OC XII, 35.
}

${ }^{8}$ Cf. Nadler, S. "Intentionality in Arnauld-Malebranche Debate" p. 74. 
falsidade material, a saber, quando elas representam o que nada é como se fosse alguma coisa" ${ }^{\prime \prime}$

Não pretendo entrar no complexo debate acerca da natureza das ideias materialmente falsas em Descartes. Acredito que a passagem ilustre o ponto já defendido por Galileu e tornado clássico com a distinção entre cognições de qualidades primárias e secundárias feita por Locke, da possível, ou provável vacuidade das cognições associadas aos sentidos. Malebranche também parece seguir a mesma linha de Descartes:

"Nós podemos dizer que as percepções que a alma tem das ideias são de
dois tipos, se tomamos 'ideia' como um termo geral que significa tudo
aquilo que a mente percebe imediatamente. Aquelas do primeiro tipo re-
presentam algo que é externo, como um quadrado, um triângulo, uma casa
etc; e aquelas do segundo tipo apenas representam aquilo que ocorre em
nós mesmos, como as nossas sensações, o prazer e a dor, a luz e as cores,
os sabores, os odores, etc. E como veremos mais adiante não são outra
coisa que maneiras de ser da alma, e é por essa razão que eu as chamo de
modificações da alma". ${ }^{10}$

Malebranche faz uma distinção entre dois tipos de cognição, que chama de forma genérica de ideias ${ }^{11}$. De um lado, temos cognições que representam coisas que são externas ao sujeito e Malebranche dá exemplos de objetos para caracterizar esse tipo de cognição. As cognições do segundo tipo são apresentadas como uma consciência que sujeito possui de si ou de eventuais alterações em seu próprio corpo. Elas não apresentariam algum conteúdo ao sujeito, tampouco um objeto externo efetivamente existente. Mas são, de pleno direito, modificações da mente, atos ou operações mentais. Malebranche, portanto, ao analisar as sensações dessa forma, estaria apresentando um caso de ato mental que não é intencional. Nadler e Jolley, por consequência, parecem ter razão em apontar que Malebranche tem uma teoria da mente que é, em certo sentido, não intencionalista. E assumir uma teoria desse tipo lhe possibilitaria apresentar uma teoria das ideias ou da cognição sem ter de lidar com as eventuais dificuldades que a controversa tese da falsidade material introduz.

\footnotetext{
${ }^{9}$ AT VII, 43; CP, 114. As referências às obras de Descartes serão feitas segundo a edição de Charles Adam e Paul Tannery (Vrin-CNRS, 11 volumes, 1974); designada pelo (AT), seguida do volume em algarismos romanos e das páginas em algarismos arábicos. O texto que foi citado, quando presente na edição brasileira das obras de Descartes, foi o da seguinte edição: Descartes, Coleção Pensadores; edição 1973; tradução de J. Guinsburg e Bento Prado Jr.. Ela será designada ao lado da referência à edição crítica da seguinte maneira: $(\mathrm{CP})$., seguido do número da página em algarismos arábicos. As traduções de passagens que não constam nessa edição são de minha responsabilidade.

${ }^{10}$ OC I, 42. Essa passagem sofreu diversas alterações durante as cinco edições da Recherche. Uma leitura adequada dela deve apresentar as possíveis diferenças entre uma versão e outra. Contudo, acredito que o ponto acerca da definição das sensações se mantém essencialmente o mesmo.

${ }^{11}$ Essa é a primeira ocorrência do termo na Recherche e não possui seu sentido propriamente malebranchista que aparecerá apenas no livro III.
} 
Porém, ao analisarmos as sensações da perspectiva da definição malebranchista de pensamento a situação se torna complexa. No que diz respeito à natureza do pensamento Malebranche também compartilha uma posição cartesiana, Descartes diz:

"Com efeito, todos os modos de pensar que experimentamos em nós podem ser referidos há dois gerais, dos quais um é a percepção ou a operação do entendimento,...Pois sentir, imaginar e entender pelo puro entendimento são apenas diversos modos de perceber,..."12

Malebranche diz algo muito semelhante:

“O espírito do homem não sendo de forma alguma material ou extenso, é sem dúvida uma substância simples, indivisível sem nenhum tipo de composição por partes; mas temos o costume de distinguir nele duas faculdades, a saber, o entendimento e a vontade,...o entendimento é aquela que recebe diversas ideias, isto é de perceber diversas coisas..."13

Malebranche, assim como Descartes, toma o espírito do homem como uma substância pensante de tal forma que todas as suas operações supõem o pensamento. Afirmar, portanto, que as faculdades do espírito do homem são o entendimento e a vontade é o mesmo que afirmar que o pensamento, enquanto substância, possui essas duas faculdades. ${ }^{14}$ Vemos, portanto, que para ambos autores, perceber é primordialmente a maneira em que o entendimento opera. Também seguindo Descartes, Malebranche ao caracterizar o entendimento menciona ideias como vimos na passagem acima: "o entendimento é aquela que recebe várias ideias, isto é percebe várias coisas" ${ }^{15}$ No que diz respeito às operações comuns do entendimento a concordância entre eles persiste. Malebranche diz na Recherche: "A alma pode perceber as coisas de três maneiras: pelo entendimento puro, pela imaginação, e pelos sentidos" ${ }^{16}{ }^{1}$ Vemos, portanto, que a sensação na medida em que é um tipo de modificação da substância pensante consiste em uma operação do entendimento o que, por conseguinte, significa que ela é uma forma de percepção. E, pela aplicação do princípio de intencionalidade defendido por Malebranche, ela deve ser concebida como uma percepção que possui um objeto efetivamente existente. Vimos que para Malebranche a determinação desse objeto é problemática. Entretanto, recusar que as sensações são intencionais é afirmar a existência de modificações da mente que não são perceptuais, o que implica na afirmação de que nem

\footnotetext{
${ }^{12}$ AT VIII-A, 18.

${ }^{13}$ OC I, 41-2.

${ }^{14}$ OC I, 123.

${ }^{15}$ AT VII, 160 Descartes diz: "Pelo nome de idéia, entendo esta forma de cada um de nossos pensamentos por cuja percepção imediata nos tornamos conscientes desses mesmos pensamentos." E, em AT VII, 181: "Mas eu mostrei, em todo lugar, de tempos em tempos, e principalmente neste lugar, que eu tomo o termo idéia para me referir para qualquer coisa que a mente percebe diretamente;...".

${ }^{16}$ OC I, 66.
} 
todo pensamento é a percepção de alguma coisa; o que é contraditório. Tampouco, o texto não nos permite classificar as sensações como não sendo modificações da mente. Nessa leitura, o problema gerado pela falsidade material das ideias também se coloca para Malebranche.

Estamos diante de uma tensão acerca do estatuto das sensações e sua eventual intencionalidade em Malebranche. No livro dedicado às sensações na Recherche ${ }^{17}$ Malebranche apresenta dois casos em que sensações são associadas a um juízo involuntário e que aparentemente possui certa intencionalidade. Cito Malebranche:

\begin{abstract}
"Quando observamos um cubo, por exemplo, é certo que todos os lados que nós vemos quase nunca fazem uma projeção ou imagem de grandeza equivalente no fundo dos nossos olhos, pois a imagem que de cada um desse lados é pintada sobre a retina ou nervo ótico, é muito parecida com um cubo observado em perspectiva, e por consequência a sensação que nós temos deveria representar as faces do cubo como desiguais, pois elas são desiguais em um cubo em perspectiva. Contudo nos os vemos como iguais, e não nos enganamos de forma alguma. Ora, nós podemos dizer que isso ocorre por uma espécie de juízo que fazemos naturalmente, saber que as faces do cubo mais distantes, e que são vistas obliquamente, não devem formar no fundo dos olhos imagens tão perfeitas quanto as faces que estão mais próximas. Mas como os sentidos não fazem nada além de sentir e não julgam, propriamente falando, é certo que esse juízo natural é apenas uma sensação composta..."18
\end{abstract}

Malebranche identifica a cognição sensível da extensão com um certo juízo natural que é, com efeito, uma espécie de correção de imagens corpóreas obtidas pela visão. A sensação, nesse sentido, seria, na percepção de uma casa, um juízo inconsciente que permite a percepção de um objeto tridimensional com todos os seus lados e ângulos equivalentes na ocasião de uma imagem bidimensional com ângulos e lados irregulares. A mente estaria implicitamente adotando regras geométricas e apresenta para si uma experiência sensória corrigida de um certo objeto, vemos uma moeda redonda e não oval. ${ }^{19}$ Malebranche chama esse juízo natural de uma sensação composta. Ao identificar esse ato corretivo com uma sensação, Malebranche dá a essa espécie de sensação, a saber, à cognição sensível das propriedades do corpo, um conteúdo representacional ${ }^{20}$ : parece nos informar acerca das propriedades do espaço e acerca das reais propriedades dos corpos. Contudo, esse processo parece ocorrer apenas com as sensações vinculadas à figura, ao tamanho e à distância de um corpo, está vinculado à cognição de qualidades primárias das coisas extensas.

\footnotetext{
17 OC I, 96-7; OC I, 130.

18 OC I, 96-7.

${ }^{19}$ Cf. NADLER, S. Malebranche and Ideas. p. 21.

${ }^{20}$ OC I, 121-2.
} 
Em relação às sensações como a luz, cor, calor, sabor, som, odor, prazer e dor (qualidades secundárias), Malebranche afirma a existência de um outro paralelo envolvendo uma forma de juízo:

“O quarto é o juízo que a alma faz que aquilo que ela sente está na sua mão, e está no fogo. Ora, esse juízo natural não é nada além de uma sensação, mas essa sensação ou esse juízo quase sempre seguido por um juízo livre, que a alma tem o hábito de fazer de tal forma que ela quase não consegue se conter". ${ }^{21}$

Malebranche nota que toda sensação desse tipo envolve também uma espécie de juízo natural e involuntário. A sensação que é gerada quando aproximamos a mão do fogo é descrita por Malebranche como "aquilo que a alma percebe está na mão e no fogo". Essa operação de determinação acerca da origem de determinada sensação pode ser considerada intencional. Essa operação vincula um conteúdo à sensação, por exemplo, 'o calor está na minha mão', tornando-a um fenômeno objeto-direcionado.

Essas operações que no livro I são denominadas de juízos por Malebranche se tornam mais claras quando ele retoma a natureza das percepções sensíveis após ter esclarecido a natureza das ideias no livro III:

"Quando percebemos alguma coisa sensível, se encontra na nossa percepção sensação ${ }^{22}$ e ideia pura. A sensação é uma modificação da nossa alma, e é Deus que a causa em nós, e ele pode causá-la, ainda que não a tenha, pois ele vê, na ideia que possui da nossa alma, que ela é capaz disso. Quanto à ideia que se encontra junto da sensação, ela é em Deus, e nós a vemos pois lhe agrada mostrá-la a nós, e Deus une a sensação à ideia, quando os objetos estão presentes, para que assim acreditemos e entretenhamos as sensações e paixões que devemos ter em relação a eles" ${ }^{23}$

Malebranche apresenta a tese da conjunção constante entre sensação e ideia. Para todo ato de cognição sensível, a modificação da alma é acompanhada por uma ideia que apresenta a essência do corpo que ocasiona a sensação. Através da percepção da ideia somos capazes de conhecer a natureza e as propriedades dos corpos. A sensação composta apresentada no primeiro livro é agora apresentada propriamente como uma composição entre paixão da alma e conteúdo representacional. A forma como as ideias representam é capaz de sempre produzir o conhecimento da natureza daquilo que é representado pela ideia. Como diz Malebranche ${ }^{24}$, a partir da cognição da ideia de alguma coisa somos capazes de saber perfeitamente as propriedades que um objeto possui, as propriedades que lhe são possíveis ou compatíveis com a natureza do objeto, as propriedades que são

\footnotetext{
${ }^{21}$ OC I, 130.

${ }^{22}$ Malebranche utiliza o termo sentiment que é empregado para designar as cognições sensíveis enquanto modificações da alma.

${ }^{23}$ OC I, 445.
} 
incompatíveis com o objeto, e em quais relações em que ele se encontra, pode ou não pode se encontrar, com outro objeto. $\mathrm{O}$ fato das ideias dos corpos serem acompanhadas das sensações é tampouco acidental. As sensações surgem não apenas da união da alma e do corpo como também para a sua preservação. Malebranche, assim como Descartes na Sexta Meditaçãa ${ }^{25}$, apresenta as sensações como signo daquilo que é adequado para conservação do corpo e daquilo que lhe é pernicioso:

"A terceira coisa que se encontra em cada uma de nossas sensações, ou aquilo que sentimos, por exemplo, quando nos aproximamos do fogo, é uma modificação da nossa alma ao qual ela está unida. Essa modificação é agradável, quando aquilo que se passa no corpo é próprio para ajudar na circulação do sangue e outras funções da vida, e a nomeamos equivocamente de calor. E essa modificação é desagradável e totalmente diferente da outra, quando o que ocorre no corpo é capaz de lhe incomodar e lhe queimar..."26

“Nós vimos também que nossos sentidos são muito fiéis e muito exatos para nos instruir das relações que todos os corpos que nos cercam possuem um com outro, mas que elas são incapazes de nos mostrar a natureza desses corpos; e, para fazer um bom uso deles, é preciso utilizá-los para conservar sua saúde e sua vida..." 27

As sensações só seriam desprovidas de intencionalidade ${ }^{28}$ quando são consideradas nelas mesmas à parte da sua relação com as ideias. Consideradas apenas como modificações da alma que ocorrem na medida em que um evento ocorre no corpo ao qual a alma está unida. Elas seriam apenas a alma existindo de uma certa maneira. Assim compreendidas, as sensações corroboram o princípio de intencionalidade de Malebranche: concebidas por si, não possuem objeto, e assim como qualquer outra modificação da alma não podem ser consideradas intencionais. Contudo, através da tese da conjunção constante, Malebranche pretende garantir que toda sensação seja acompanhada de uma ideia em Deus, assim possuindo um objeto. $\mathrm{O}$ problema da intencionalidade das sensações não parece diferir, para Malebranche, do problema da intencionalidade das operações da imaginação ou até do entendimento puro, como pretende explicar nos livros II e III da Recherche. Tomadas isoladamente, as modificações da alma não são capazes de obter os requisitos necessários para se mostrarem intencionais. Disso, entretanto, não decorre que não são intencionais para Malebranche.

${ }^{24}$ Cf. OCM I, 450; PS, 204-5.

${ }^{25}$ AT VII, 81; AT VII, 83; AT VII, 87.

${ }^{26}$ OC I, 143.

${ }^{27}$ OC I, 186-7.

${ }^{28}$ Há intérpretes que defendem a atividade de significação das sensações como uma atividade mental, ainda que não equivalente a intencionalidade relacionada propriamente ao entendimento puro, de certa forma intencional. Nas passagens citadas, Malebranche parece ir em direção a essa tese. Contudo, é preciso verificar se as sensações, assim concebidas, aderem ao seu princípio de intencionalidade. Cf. SIMMONS, A. "Are Cartesian Sensations Representational?" 
Ao contrário, isso apenas denota que a sua intencionalidade não pode ser derivada da sua própria natureza.

Em grande medida a dificuldade de estabelecer a intencionalidade de um ato mental e, especialmente das sensações, em Malebranche repousa na sua interpretação forte do objeto intencional. Essa interpretação, por sua vez, pode ter a sua origem na relação entre a utilização dos termos 'pensar' e 'ver' na sua teoria da cognição. $\mathrm{O}$ quase que constante paralelo feito por Malebranche entre a percepção de ideias com a percepção de objetos materiais ${ }^{29}$, parece nos levar a tomar sua teoria das ideias como restrita a esses casos de cognição; seria uma teoria da visão em sentido estrito, e não abrangeria todo espectro das cognições humanas. Na abertura da investigação acerca das ideias, especificamente na segunda parte do terceiro livro da Recherche, Malebranche apresenta o argumento posteriormente conhecido como o argumento da "alma caminhante"

“Creio que todo mundo está de acordo em que nós não percebemos os objetos que estão fora de nós por eles mesmos. Vemos o sol, as estrelas e uma infinidade de objetos fora de nós, e não é verossímil que a alma saia do corpo e que vá, por assim dizer, passear pelos céus para naquele contemplar todos esses objetos. Ela não vê, portanto, tais objetos por eles mesmos; e o objeto imediato de nosso espírito, quando ele vê o sol, por exemplo, não é o sol, mas alguma coisa que está intimamente unida à nossa alma, e é o que chamo de 'ideia'. Assim, por essa palavra 'ideia', entendo somente o que é o objeto imediato ou mais próximo do espírito, quando ele percebe algum objeto, isto é, o que afeta e modifica o espírito com a percepção que ele tem de um objeto". ${ }^{31}$

Encontramos nessa passagem dois momentos distintos. O primeiro momento é o estabelecimento de um argumento acerca da natureza da percepção de objetos externos. E, em um segundo momento, Malebranche introduz a noção de ideia apoiando-se na conclusão do argumento anterior. Em relação ao argumento, o texto oferece as seguintes sentenças que sugerem a enunciação da tese a ser estabelecida, duas premissas e uma conclusão; podendo ser, assim, rearranjado:

(a) Creio que todo mundo está de acordo em que nós não percebemos os objetos fora de nós por eles mesmos; ${ }^{32}$

(b) Vemos o sol, as estrelas e uma infinidade de objetos fora de nós...;

(c) ...e não é verossímil que a alma saia do corpo e que vá, por assim dizer, passear pelos céus para naquele contemplar todos esses objetos;

(d) Ela não vê, portanto, tais objetos por eles mesmos.

\footnotetext{
${ }^{29}$ Dentre as inúmeras passagens, cf. OC I, 413-4; OC XII, 38.

${ }^{30}$ Expressão cunhada por John Yolton. Cf. Perceputal Acquaintance. p. 48.

${ }^{31}$ OC I, 413-4.

32 Estou tomando a expressão 'perceber por si mesmo' como equivalente à 'perceber imediatamente'; opondo-se 'a perceber por (mediante) outro'.
} 
Ao assumirmos, como Malebranche o faz, que há percepção dos objetos externos, ainda que a existência de tais objetos não esteja suposta, parece necessário, dado a maneira em que ele concebe a natureza da percepção, que aceitemos que há percepção imediata de algo. Disto não se segue que não tenhamos percepções falsas ou de objetos inexistentes, apenas que não podemos ter percepções vazias. Essa abordagem relacional da percepção, feita por Malebranche, exige que mesmo nos casos de percepções falsas algo responda pelo objeto da percepção. Assim, recusar que em toda percepção há algo imediatamente percebido nos levaria a um regresso ao infinito de objetos intermediários de percepção o que comprometeria a própria inteligibilidade do ato de perceber. Dado o caráter transitivo da percepção, toda percepção é percepção de alguma coisa, temos que supor, ao menos, que há algo que percebe e que há algo que é percebido. Não estou aqui me comprometendo com a natureza desses elementos necessários para a percepção, apenas busco salientar que o argumento de Malebranche propicia a esta observação acerca da constituição da intencionalidade do ato de perceber.

Ainda que de uma maneira aparentemente imprecisa, Malebranche apresenta, no item (c), uma condição para que a alma, ou o sujeito, perceba os objetos externos por eles mesmos. Para que a alma os possa perceber dessa forma, seria preciso que ela ou bem estabeleça um contato, ou vínculo, imediato com os objetos externos ou haja uma mútua presença entre eles; esse princípio sendo caracterizado pela passagem da "alma caminhante", a saber, "..que a alma saia do corpo e que vá, por assim dizer, passear pelos céus para naquele contemplar todos esses objetos". Contudo, não é explícita a razão apresentada por Malebranche para defender tal princípio. $\mathrm{Na}$ medida em que aquilo que aqui denominei como cláusula do contato ou da presença ainda não está adequadamente apresentada, não dispomos dos elementos necessários para fazer a passagem de percepção imediata para a necessidade de um contato. Malebranche emprega 'percepção', aparentemente como percepção sensível. ${ }^{33}$ Do fato de que objetos externos estão distantes de nós, pretende-se afirmar que não podemos vê-los sem um intermediário que está intimamente unido à alma. E isso parece significar tanto que deve haver algum objeto que é localmente presente e que tal objeto deve exercer uma atividade causal no sujeito. $\mathrm{O}$ argumento acima citado parece nos levar a compreender que as ideias são necessárias para a visão das coisas externas.

Contudo, nas passagens que citamos acerca do princípio de intencionalidade acima Malebranche está tomando 'ver' como equivalente ao ato de 'pensar'. Temos isso explicitamente nas comparações entre a afirmação que

${ }^{33}$ Há um extenso debate acerca da interpretação correta desse argumento em Malebranche. Cf. NADLER, S. Malebranche and Ideas. cap. 2. E LENNON, T. "Malebranche's Argument for Ideas and Its Systematic Importance". Não estou aqui me comprometendo com a posição que, de fato, Malebranche está apelando para a necessidade de contato espacial entre a mente e seu objeto para que ocorra uma cognição. A mera aparência é suficiente para o meu ponto. 
o nada é tampouco visível ou inteligível. E, na própria manifestação do princípio voir rien (ver o nada, é nada ver; pensar o nada, não é pensar), esse paralelo fica claro. Nesse caso, perceber ou ver não estaria sendo empregado apenas para os casos de cognição de objetos materiais, mas para todos os casos de cognição humana que envolvem algum tipo de pensamento. $\mathrm{O}$ argumento apresentado por Malebranche, na passagem dos Entretiens, aborda a necessidade de um objeto efetivamente existente para o pensamento de forma irrestrita. Malebranche diz: "quando eu penso em um círculo, em um número, no ser, no infinito, ou em um certo ser finito, eu penso em realidades." 34

A teoria das ideias, embora empregue, nesse argumento, o vocabulário do sensível, é apenas introduzida no exame do entendimento puro, ou seja, na análise das operações do pensamento que são dissociadas da imaginação e da sensação. Apesar do argumento da alma caminhante partir, aparentemente, de uma consideração da percepção como vinculada a objetos externos, Malebranche não parece tomar 'percepção' como sendo exclusivamente relacionada aos objetos materiais. Assim, não parece, em um primeiro momento, correto caracterizar a teoria das ideias de Malebranche como uma teoria apenas acerca da percepção dos objetos materiais. Quando Malebranche, de acordo com o que acabamos de verificar, menciona 'percepção' parece ter em mente toda atividade que envolve o pensamento e que, portanto, sua teoria das ideias, seria uma teoria que pretende explicar a atividade cognitiva humana como um todo. Todo ato do espírito do homem é um ato de pensamento. Atos de pensamento são operações do entendimento ou da vontade. $\mathrm{O}$ entendimento se manifesta através de percepções ou do recebimento de ideias. Essas percepções ou recebimento de ideias são da ordem dos sentidos, da imaginação e do entendimento puro. ${ }^{35}$

Ao afirmar que toda percepção é a percepção de algum objeto efetivamente existente, Malebranche parece estar adotando o modelo da intencionalidade que é atribuído à visão; e, nesse sentido, leva a comparação entre 'pensar' e 'ver' às últimas consequências. Se a substância pensante possui como ato paradigmático a percepção, e, nesse sentido, pensar é perceber e, por sua vez, perceber é fortemente associado aos objetos extensos, essa associação também é válida para o pensamento. O modelo de explicação da percepção dos objetos extensos é repassado à percepção associada ao pensamento. Isso, contudo, não significa dizer que o pensamento seja restrito à percepção das coisas materiais, mas que o modelo de cognição na percepção das coisas materiais é o mesmo da cognição envolvida em atos de pensamento.

Esses requisitos possuem plausibilidade quando estamos falando de percepção sensível, mas teriam em relação ao pensamento? Para pensarmos no

\footnotetext{
${ }^{34}$ OC XII, 35.

${ }_{35}$ Até mesmo nas operações da vontade é preciso percepção. A vontade supõe para sua operação um objeto que deve ser percebido.
} 
sol, nas estrelas, e numa infinidade de objetos externos a nós não parece ser o caso que seja necessário que tenhamos esses objetos no nosso campo de visão, tampouco seus supostos intermediários. Se tomarmos 'perceber', em um sentido estrito, como a visão de coisas materiais, parece ser correta a afirmação da necessidade da postulação de objetos efetivamente existentes. Contudo, tal necessidade não parece se aplicar a perceber em um sentido amplo e, assim, ao pensar. Malebranche ao tomar como equivalente 'percepção' (em um sentido lato), como aquilo que é associado ao pensamento, com 'percepção' (em sentido estrito), como aquilo que é associado às cognições através dos sentidos, não parece levar em consideração uma possível distinção que pode ser feita entre conteúdo e objeto. ${ }^{36}$

Tanto 'ver' como 'pensar' parecem requerer conteúdo. Não posso ver sem ver alguma coisa, assim como não posso pensar sem pensar alguma coisa. Mas dizer isso é apenas constatar o direcionamento intrínseco para alguma coisa e isso não parece requerer um objeto efetivamente existente. Podemos pensar na fonte da juventude e nosso pensamento tem um conteúdo (a fonte da juventude), mas não tem objeto (não há uma fonte da juventude). A natureza desse conteúdo não precisa ser as ideias, no seu sentido malebranchista. Ver, ao contrário, parece requerer conteúdo e objeto. $\mathrm{O}$ ato de visão supõe a afecção de algum objeto ao aparato visual. Mesmo nos casos de visão deturpada parece haver a necessidade de postular a existência de um causador. Nesse caso, estaríamos defendendo que perceber em sentido lato e perceber em sentido estrito é uma distinção filosoficamente relevante e que pensar e ver são atos qualitativamente distintos. Através da distinção entre conteúdo e objeto somos capazes de mostrar que pensar requer apenas conteúdo e ver requer conteúdo e objeto.

Malebranche não ignora, porém, tal distinção entre conteúdo e objeto. Essa é, ainda que colocada em outros termos, justamente a sua polêmica com Arnauld. Malebranche não aceita a atribuição de uma realidade objetiva que é vinculada às modificações da mente como suficiente para dar conta da intencionalidade do pensamento. Os pensamentos possuem um conteúdo que é dependente da existência de um objeto. A mera discriminação de um conteúdo não é suficiente para explicar a natureza do pensamento. Isso seria apenas esclarecer a fenomenologia do ato de pensar. Nenhuma característica que possa a vir a ser atribuída a algum conteúdo mental é capaz de possuir todas as características aventadas a um objeto requerido por Malebranche, pois elas não seriam capazes de dar efetivamente um objeto distinto da operação mental. Malebranche não parece estar disposto a trocar um modelo de intencionalidade que embora, em um primeiro momento, seja restritivo, e o leve a defender uma teoria das ideias como entidades realmente distintas da mente, por um modelo de explicação onde é necessário postular um nível de existência que é próprio das ati-

${ }^{36}$ Cf. COOK, M. "Malebranche e Arnauld: The Argument for Ideas". 
vidades mentais e que supostamente explicaria como, através do pensamento, somos capazes de conhecer o mundo. Talvez sua empreitada seja mal fadada e que ele também lance mão de uma ontologia obscura para explicar a natureza das ideias; e que, ao fim, sua teoria seja incorreta. $\mathrm{O}$ ponto importante é que o que o leva a defender essa posição parece ser apenas a extração de algumas consequências que estavam implícitas na comparação feita entre pensar e perceber.

\section{Referências Bibliográficas:}

Obras de Malebranche:

Oeuvres Complètes de Malebranche. Ed. André Robinet. J. Vrin. Paris. 1958-1970.

Obras de Descartes:

Oeuvres de Descartes. Ed. Charles Adam e Paul Tannery. J. Vrin. Paris. 1964-1976.

Literatura Secundária:

ALQUIÉ, F. Le Cartésianisme de Malebranche. J. Vrin. Paris. 1974.

COOK, M. "Malebranche e Arnauld: The Argument for Ideas". In: The Great Arnauld. Ed. Kremer, E. University of Toronto Press. Toronto. 1994. p. 69-89.

JOLLEY, N. The Light of the Soul. Oxford University Press. Oxford. 1990.

LENNON, T. "Malebranche's Argument for Ideas and Its Systematic Importance" In: North American Kant Society: Minds, Ideas, and Objects. Vol. 2; 1992. p. 57-73.

NADLER, S. Malebranche and Ideas. Oxford University Press. Oxford. 1992. Arnauld and The Cartesian Philosophy of Ideas. Princeton University Press. Princeton. 1989. "Intentionality in the Arnauld-Malebranche Debate" In: North American Kant Society: Minds, Ideas, and Objects. Vol. 2 1992. p. 73-85.

SIMMONS, A. "Are Cartesian Sensations Representational?" In: Noûs, Vol. 33; No. 3; 1999. p. 347-369.

YOLTON, J. Perceptual Acquaintance From Descartes to Reid. University of Minnesota Press. Minneapolis. 1984.

Endereço do Autor:

Av. Osvaldo Aranha 1407, complemento 07

Bom Fim

90035-191 Porto Alegre - RS

pricladnitzky@gmail.com 